\title{
Analisis Kondisi Operasi Kolom Distilasi pada Purifikasi Produk Green Diesel
}

\author{
Budiman Achmadi ${ }^{1}$, Maulia Rizki ${ }^{2}$, Puti Nurul Amalia ${ }^{* 3}$, Ahmad Zikri ${ }^{4}$ \\ ${ }^{1}$ Program Studi Teknik Energi, Jurusan Teknik Kimia, \\ Politeknik Negeri Sriwijaya, Indonesia \\ Email: 1putinurul243@gmail.com
}

\begin{abstract}
Abstrak
Green Diesel merupakan salah satu sumber energi alternatif yang dapat diperbaharui dan maupun untuk mengurangi ketergantungan energi nasional terhadap energi fosil. Green Diesel diproduksi dari minyak tumbuhan. Minyak nabati yang dapat digunakan sebagai bahan baku adalah minyak jelantah. Green Diesel yang dihasilkan masih banyak mengandung bahan kimia didalamnya, sehingga masih perlu dilakukan proses pemisahan bahan kimia tersebut. Proses pemisahan yang dilakukan yaitu berdasarkan perbedaan kecepatan atau kemudahan menguap (volatilitas) bahan. Pada penelitian ini dilakukan running sebanyak 5 kali dengan waktu proses selama 1 jam dan variasi volume reboiler sebesar $1000 \mathrm{~mL}, 1500 \mathrm{~mL}, 2000 \mathrm{~mL}, 2500 \mathrm{~mL}$, dan $3000 \mathrm{~mL}$. Dari hasil running tersebut diperoleh waktu running optimum proses distilasi green diesel yaitu pada running ke 2 dengan volume reboiler $1500 \mathrm{~mL}$. Dari 5 kali running tersebut didapatkan distilat dari beberapa tray dan dilakukan analisa. Adapun hasil analisa tersebut yaitu densitas dari tray ke 1 sebesar 0,7624-0,7745 $\mathrm{gr} / \mathrm{cm}^{3}$, viskositas dari tray ke 1 sebesar 2,07-2,62 mm²/s, titik nyala dari tray ke 1 sebesar $55-57,8^{\circ} \mathrm{C}$, nilai kalor dari tray ke 1 sebesar 44,9 MJ/kg, dan cetane number dari tray ke 1 sebesar 100,7 CN.
\end{abstract}

Kata kunci: Green Diesel, Kolom Distilasi.

\section{Analysis of The Operating Conditions of The Distillation Column on The Purification of Green Diesel Products}

\begin{abstract}
Green Diesel is an alternative energy source that can be used and or to reduce national energy dependence on fossil energy. Green Diesel is produced from plant oils. Vegetable oil that can be used as raw material is used cooking oil. Green Diesel produced still contains a lot of chemicals in it, so it is still necessary to process the separation of these chemicals. The separation process is carried out based on differences in the speed or ease of evaporating the material. In this study, run 5 times with a processing time of 1 hour and variations in the reboiler volume of $1000 \mathrm{~mL}, 1500 \mathrm{~mL}, 2000 \mathrm{~mL}, 2500 \mathrm{~mL}$, and $3000 \mathrm{~mL}$. From the results of the running, the optimum running process for green diesel distillation was obtained, namely on the 2nd run with a reboiler volume of $1500 \mathrm{~mL}$. From these 5 runs, distillate was obtained from several trays and analyzed. The results of the analysis are the density of the 1st tray is 0.7624-0.7745 $\mathrm{gr} / \mathrm{cm}^{3}$, the viscosity of the 1st tray is 2.07-2.62 $\mathrm{mm}^{2} / \mathrm{s}$, the flash point of the 1 st tray is $55-57,8^{\circ} \mathrm{C}$, the calorific value of the 1 st tray is $44.9 \mathrm{MJ} / \mathrm{kg}$, and the cetane number of the 1st tray is $100.7 \mathrm{CN}$.
\end{abstract}

Keywords: Green Diesel, Distillation Column.

\section{PENDAHULUAN}

Minyak bumi merupakan bahan bakar fosil yang penggunaannya sebagai bahan baku untuk bahan bakar minyak, bensin, dan banyak produk-produk kimia. Permasalahan terbesar adalah konsumsi Bahan Bakar Minyak (BBM) yang terus naik tiap tahunnya, dilansir pada tahun 2030 akan naik mencapai 107 juta kilo liter/tahun dan sekitar 50\% atau tepatnya 55,64\% dari BBM tersebut dipenuhi oleh impor. Penggunaan BBM yang terus menerus dan cenderung meningkat akibat pertumbuhan penduduk dan industri, sementara cadangan minyak yang semakin menipis dan tidak dapat diperbaharui, sangat potensial menimbulkan krisis energi pada masa yang akan datang.

Pemanfaatan Energi Baru Terbarukan (EBT) di Indonesia baru mencapai 6\% dari total potensi EBT yang ada. Green diesel salah satu pemanfaatan yang berpotensi menjadi dasar utama di dalam rencana pengembangan EBT yang menargetkan porsi energi terbarukan (EBT) dalam bauran energi mencapai 13,4\% pada tahun 2020. 
Porsi ini akan mengalami peningkatan hingga 19,5\% pada tahun 2024. Bertahap pada 2021 mencapai 14,5\%, 2022 mencapai 15,7\% dan 2023 mencapai 17,9\% (Kementerian ESDM, 2020). Sementara bauran energi minyak yang merupakan energi fosil bumi akan menurun menjadi sekitar $20 \%$ pada 2050.

Bahan bakar yang bersumber dari energi terbarukan kini menjadi suatu alternatif yang sangat menarik perhatian sebagai pengganti bahan bakar fosil. Salah satunya adalah green diesel. Green diesel adalah senyawa alkana yang diproduksi menggunakan minyak nabati (minyak sawit, minyak biji-bijian, minyak jarak dan lainlain) yang diolah dengan metode hydrotreating sehingga memiliki sifat-sifat mirip bahan bakar diesel. Berbeda dengan teknologi produksi biodiesel yang dihasilkan melalui proses transesterifikasi, green diesel diperoleh dengan proses hydrotreating, yang merupakan reaksi senyawa organik dengan menggunakan hidrogen bertekanan untuk menghilangkan oksigen serta heteroatom lainnya, yaitu nitrogen, sulfur, dan klorin (De S, dkk., 2015).

Green diesel yang dihasilkan masih banyak mengandung bahan kimia didalamnya, sehingga masih perlu dilakukan proses pemisahan bahan kimia tersebut. Proses pemisahan yang dilakukan yaitu berdasarkan perbedaan kecepatan atau kemudahan menguap (volatilitas) bahan. Pada penelitian ini akan dirancang alat distilasi dengan jenis kolom dan menggunakan metode batch, bahan konstruksi yang digunakan adalah stainless steel dimana bahan jenis ini tahan terhadap korosi dan temperatur yang tinggi. Sehingga dapat meminimalisir terjadinya kebocoran pada saat berlangsungnya proses distilasi, bahwasannya proses distilasi berlangsung dalam temperatur yang cukup tinggi.

\section{METODE PENELITIAN}

\subsection{Alat dan Bahan}

Peralatan yang digunakan dalam penilitian ini yaitu seperangkat alat distilasi jenis Bubble Cup Tray, piknometer, viscometer, corong pisah, statif, gelas ukur, neraca analitik, gelas kimia, kondensor, dan alat flash point.

Bahan-bahan yang digunakan dalam penelitian ini adalah green diesel yang diperoleh dari kelompok sebelumnya

\subsection{Metode Penelitian}

Green diesel yang dihasilkan dari proses sebelumnya masih banyak mengandung bahan-bahan kimia lain didalamnya, sehingga dibutuhkan suatu proses yang mampu memisahkan bahan-bahan kimia tersebut. Dalam penelitian ini digunakan seperangkat alat distilasi jenis bubble cup tray, dimana untuk tahapan proses pemurnian ini yaitu memasukan green diesel kedalam reboiler dengan variasi volume $1500 \mathrm{ml}, 2500 \mathrm{ml}$, dan 3000ml, kemudian green diesel tersebut dipanaskan dengan variasi temperature $240^{\circ} \mathrm{C}, 260^{\circ} \mathrm{C}, 280^{\circ} \mathrm{C}, 300^{\circ} \mathrm{C}$, dan $320^{\circ} \mathrm{C}$. Uap dari proses pemanasan menuju ke kolom distilasi, uap tersebut kemudian di kondensasi di unit kondenser dengan variasi temperature kondenser $17^{\circ} \mathrm{C}, 14^{\circ} \mathrm{C}, 11^{\circ} \mathrm{C}, 8^{\circ} \mathrm{C}$, dan $5^{\circ} \mathrm{C}$. Uap yang telah dikondensasi dari tiap-tiap tray akan ditampung didalam gelas ukur untuk di analisa. Analisa tersebut terdiri dari analisa karakteristik bahan bakar cair yaitu analisa Densitas (ASTM D-1298), Viskositas (ASTM D-1298), Titik nyala (ASTM D-93), Angka setana, Nilai kalor, dan GC-MS

\section{HASIL DAN PEMBAHASAN}

\subsection{Karakteristik Green Diesel yang Dihasilkan}

Green Diesel dari proses distilasi yang dihasilkan memiliki wujud cair dan berwarna bening kekuningan, sebelum dilakukan distilasi bahan baku berwarna coklat kehitaman, hal ini juga menunjukkan proses distilasi terbilang berhasil, dengan nilai densitas sebesar $0,7745 \mathrm{gr} / \mathrm{cm}^{3}$, viskositas sebesar $2,62 \mathrm{~mm}^{2} / \mathrm{s}$, titik nyala sebesar $57,8^{\circ} \mathrm{C}$, nilai kalor sebesar 44,9 MJ/kg, dan angka setana sebesar 100,7 CN. Semua hasil analisa diatas telah menunjukkan keberhasilan distilasi karena sesuai standar Green Diesel European Standard EN15940:2016/A1:2018. Semakin tinggi densitas maka diameter tetesan bahan bakar dan menghambat proses atomisasi (Holilah dkk., 2013). Semakin tinggi nilai kalor suatu bahan bakar maka energi yang dihasilkan pun akan semakin efisien, karena menghasilkan panas yang lebih besar dengan massa yang sedikit (Irzon, 2012).

\subsection{Pengaruh Volume Reboiler Pada Distilasi Green Diesel}

Analisa pengaruh perubahan volume reboiler terhadap \% distilat yang dihasilkan. Distilat Tray ke 1 terlihat bahwa pada running ke 1 volume reboiler sebanyak $1000 \mathrm{~mL}$ dengan \% distilat sebesar 37,70, pada running ke 2 
volume reboiler sebanyak $1500 \mathrm{~mL}$ dengan $\%$ distilat sebesar 38,40, pada running ke 3 volume reboiler sebanyak $2000 \mathrm{~mL}$ dengan \% distilat sebesar 38,15, pada running ke 4 volume reboiler sebanyak $2500 \mathrm{~mL}$ dengan $\%$ distilat sebesar 36,48, dan pada running ke 5 volume reboiler sebanyak $3000 \mathrm{~mL}$ dengan $\%$ distilat sebesar 36,53. Dari data diatas dapat dilihat bahwa untuk hasil yang optimum berada pada running ke 2 dengan volume reboiler sebanyak $1500 \mathrm{~mL}$ dan \% distilat yang dihasilkan sebesar 38,40. Hasil analisa dapat dilihat pada grafik yang disajikan pada Gambar 1.

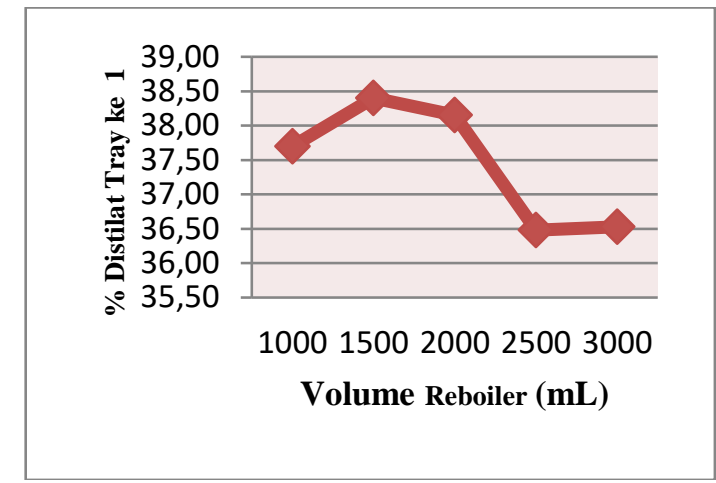

Gambar 1. Grafik Volume Reboiler Terhadap \% Distilat Tray ke 1

\section{3. \% Volume Distilat Tray ke 1 Terhadap Densitas}

Volume Distilat Tray ke 1 Terhadap Densitas dapat dilihat bahwa pada volume distilat 37,70\% didapat densitas sebesar $0,7666 \mathrm{gr} / \mathrm{cm}^{3}$, pada volume distilat $38,40 \%$ didapat densitas sebesar $0,7745 \mathrm{gr} / \mathrm{cm}^{3}$, pada volume distilat $38,15 \%$ didapat densitas sebesar $0,7611 \mathrm{gr} / \mathrm{cm}^{3}$, pada volume distilat $36,48 \%$ didapat densitas sebesar $0,7624 \mathrm{gr} / \mathrm{cm}^{3}$, dan pada volume distilat $36,53 \%$ didapat densitas sebesar $0,7624 \mathrm{gr} / \mathrm{cm}^{3}$. Jadi, dapat disimpulkan bahwa densitas diatas memenuhi densitas green diesel berdasarkan Green Diesel European Standars EN15940:2016/A1:2018 yaitu sebesar 765-800 kg/m $\mathrm{m}^{3}$ atau sama dengan 0,765-0,8 gr/ $\mathrm{cm}^{3}$. Pada umumnya, densitas bahan bakar harus memiliki nilai densitas yang rendah karena apabila nilai densitas bahan bakar terlalu tinggi maka akan meningkatkan keausan mesin dan menyebabkan kerusakan pada mesin (Setiawan \& Edwar, 2012). Hasil analisa dapat dilihat pada grafik yang disajikan pada Gambar 2.

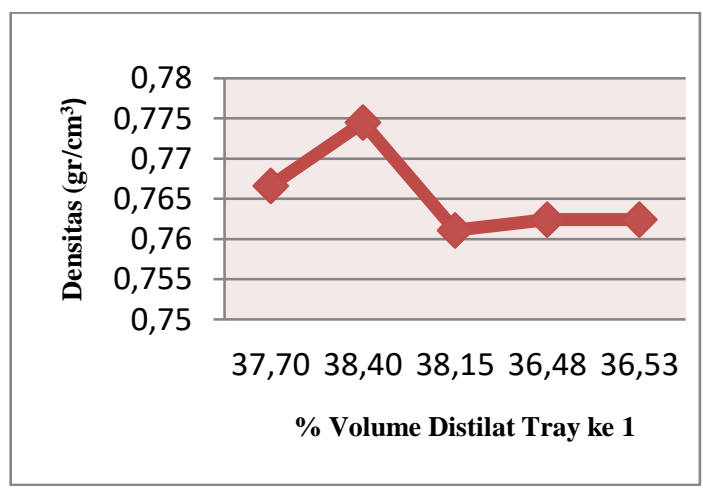

Gambar 2. Grafik \% Volume Distilat Tray ke 1 Terhadap Densitas

\section{4. \% Volume Distilat Tray ke 1 Terhadap Viskositas}

$\%$ Volume Distilat Tray ke 1 Terhadap Viskositas dapat dilihat bahwa pada volume distilat 37,70\% didapat viskositas sebesar $2,07 \mathrm{~mm}^{2} / \mathrm{s}$, pada volume distilat $38,40 \%$ didapat viskositas sebesar $2,62 \mathrm{~mm}^{2} / \mathrm{s}$, pada volume distilat $38,15 \%$ didapat viskositas sebesar $2,37 \mathrm{~mm}^{2} / \mathrm{s}$, pada volume distilat $36,48 \%$ didapat viskositas sebesar $2,29 \mathrm{~mm}^{2} / \mathrm{s}$, dan pada volume distilat $36,53 \%$ didapat viskositas sebesar $2,18 \mathrm{~mm}^{2} / \mathrm{s}$. Jadi, dapat disimpulkan bahwa viskositas diatas memenuhi viskositas green diesel berdasarkan Green Diesel European Standars EN15940:2016/A1:2018 yaitu sebesar 2,0-4,5 mm²/s. Nilai densitas dan viskositas berbanding lurus, maka ketika densitas menurun, nilai viskositas juga menurun dan sebaliknya, semakin besar nilai densitas maka nilai viskositas akan semakin besar. Hal ini disebabkan kerapatan antar molekul yang semakin rapat pada minyak, maka gaya kohesi pada minyak akan semakin besar sehingga kekentalan minyak semakin tinggi (Fathona, 2019). Hasil analisa dapat dilihat pada grafik yang disajikan pada Gambar 3. 


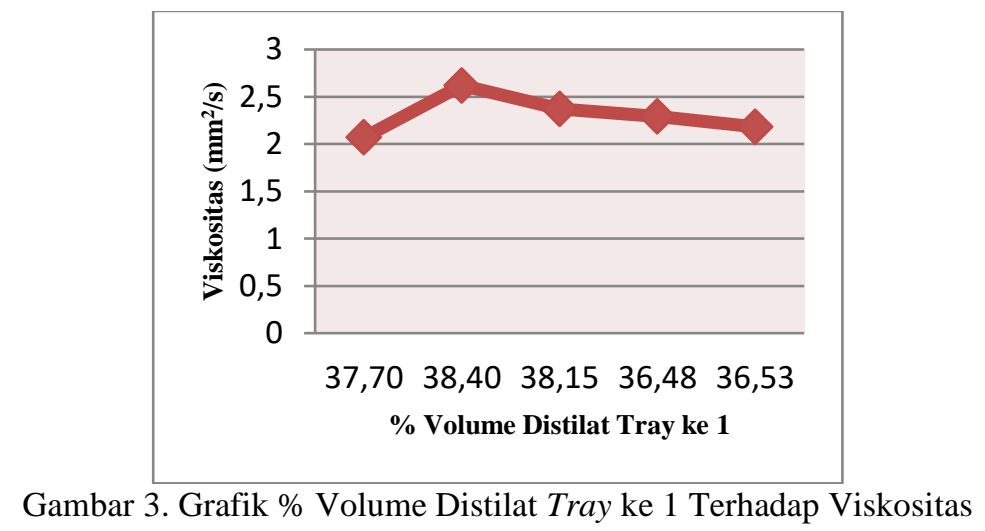

\section{5. \% Volume Distilat Tray ke 1 Terhadap Titik Nyala}

$\%$ Volume Distilat Tray ke 1 Terhadap Titik Nyala dapat dilihat bahwa pada volume distilat 37,70\% didapat titik nyala sebesar $56,9^{\circ} \mathrm{C}$, pada volume distilat $38,40 \%$ didapat titik nyala sebesar $57,8^{\circ} \mathrm{C}$, pada volume distilat $38,15 \%$ didapat titik nyala sebesar $56,9^{\circ} \mathrm{C}$, pada volume distilat $36,48 \%$ didapat titik nyala sebesar $55,5^{\circ} \mathrm{C}$, dan pada volume distilat $36,53 \%$ didapat titik nyala sebesar $55^{\circ} \mathrm{C}$. Jadi, dapat disimpulkan bahwa titik nyala diatas memenuhi titik nyala green diesel berdasarkan Green Diesel European Standars EN15940:2016/A1:201 yaitu sebesar $55^{\circ} \mathrm{C}$. Titik nyala yang terlalu tinggi juga dapat menyebabkan keterlambatan penyalaan, namun titik nyala yang terlalu rendah juga tidak diinginkan karena akan menyebabkan timbulnya detonasi yaitu ledakan-ledakan kecil yang terjadi sebelum bahan bakar masuk ke ruang bakar (Ni'matul Izza, 2011). Hasil analisa dapat dilihat pada grafik yang disajikan pada Gambar 4.

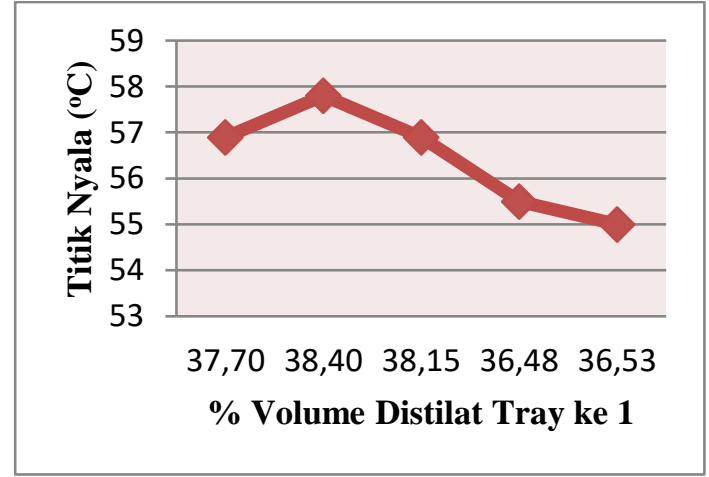

Gambar 4. Grafik \% Volume Distilat Tray ke 1 Terhadap Titik Nyala

\subsection{Analisa Nilai Kalor Green Diesel}

Nilai kalor merupakan jumlah energi panas yang dilepaskan tiap satuan massa. Pada penelitian ini, pengukuran nilai kalor dilakukan pada sampel tray ke 1. Pengukuran nilai kalor dilakukan dengan menggunakan bomb calorimeter pada sampel dengan persen distilat tertinggi. Nilai kalor yang didapat sebesar 44,9 MJ/kg atau sama dengan $10736.4051 \mathrm{cal} / \mathrm{gr}$. Nilai kalor ini mendekati nilai kalor Green Diesel European Standars EN15940:2016/A1:201 sebesar 43,70-44,5 MJ/kg atau sama dengan 10444,3-10635,5 cal/gr. Semakin tinggi nilai kalor suatu bahan bakar maka energi yang dihasilkan pun akan semakin efisien, karena menghasilkan panas yang lebih besar dengan massa yang sedikit (Irzon, 2012).

\subsection{Analisa Cetane Number Green Diesel}

Cetane number merupakan indikator yang menunjukkan seberapa cepat bahan bakar mesin Diesel yang diinjeksikan ke ruang bakar bisa terbakar secara spontan. Semakin cepat suatu bahan bakar mesin Diesel terbakar setelah diinjeksikan ke dalam ruang bakar, semakin baik cetane number bahan bakar tersebut. Cetane number yang didapat sebesar 100,7 CN. Nilai tersebut melebihi nilai minimum dari cetane number green diesel yaitu sebesar 70 CN berdasarkan Green Diesel European Standard EN15940:2016/A1:2018. Semakin tinggi nilai cetane number maka semakin baik kualitas green diesel 


\subsection{Analisa GC-MS Green Diesel}

Analisa GC-MS (Gas Chromatography-Mass Spectroscopy) adalah analisa yang digunakan untuk mengukur jenis kandungan senyawa dalam suatu sampel baik secara kualitatif dan kuantitatif. Pengukuran GCMS pada umumnya hanya dibatasi untuk senyawa berwujud gas atau cairan yang mempunyai uap minimal 10-10 torr.

Berdasarkan hasil tanda uji GC-MS menunjukkan komponen, fraksi, dan komposisi senyawa yaitu, untuk komponen $<\mathrm{C}_{5}$ fraksi gas dengan komposisi senyawa $0 \%$, untuk komponen $\mathrm{C}_{6}-\mathrm{C}_{10}$ fraksi bensin dengan komposisi senyawa $13,71 \%$, untuk komponen $\mathrm{C}_{11}-\mathrm{C}_{14}$ fraksi kerosene dengan komposisi senyawa $8,71 \%$, dan untuk komponen $\mathrm{C}_{15}-\mathrm{C}_{17}$ fraksi solar/ diesel dengan komposisi senyawa 77,58\%. Dari data yang diperoleh diatas hal tersebut membuktikan bahwa komposisi senyawa komponen tertinggi yaitu $\mathrm{C}_{15}-\mathrm{C}_{17}$ dengan fraksi solar/ diesel sebanyak $77,58 \%$.

\section{KESIMPULAN}

Berdasarkan hasil penelitian yang telah dilakukan, dapat disimpulkan bahwa, kondisi running optimum proses distilasi green diesel yaitu pada running ke 2 dengan volume reboiler $1500 \mathrm{~mL}$, waktu proses 1 jam, dan volume distilat sebesar $850 \mathrm{~mL}$. Kemudian untuk karakteristik produk yang dihasilkan memiliki sifat yang mirip dengan Green Diesel European Standars EN15940:2016/A1:2018 ditinjau dari sifat fisik dan kimianya berupa densitas, viskositas, titik nyala, nilai kalor, dan cetane number..

\section{DAFTAR PUSTAKA}

[1] Ameen, Mariam, M. T. Azizan, A. Ramli, S. Yusup, dan M. S. Alnarabiji. Catalytic Hydrodeoxygenation of Rubber Seed Oil over Sonochemically Synthesized Ni-Mo/ $\gamma$-Al2O3 Catalyst for Green Diesel Production. Ultrasonics Sonochemistry, 2018

[2] A. Parhan. 2014, http://eprints.polsri.ac.id/323/3/BAB\%20II.pdf. (Diakses tanggal 21 Maret 2021).

[3] Ayubdova. "Macam-macam Distilasi, Pengertian Distilasi, Prinsip Distilasi," 2020. (Diakses tanggal 03 Mei 2021).

[4] S. De, B. Saha, and R. Luque, "Hydrodeoxygenation Processes: Advances on Catalytic Transformations of Biomass-Derived Platform Chemicals into Hydrocarbon Fuels," Bioresource Technology. vol. 178, pp. 108-118, 2015

[5] S. L. Douvartzides, N. D. Charisiou, and K. N. Papageridis, "Green Diesel: Biomass Feedstocks , Production Technologies, Catalytic Research , Fuel Properties and Performance in Compression Ignition Internal Combustion Engines," vol. 12, no, 5, 2019

[6] A. Sutomo, "Metode Pemisahan Kimia," 2017. https://www.slideshare.net/B2C015004/ppt-distilasi-ari. (Diakses tanggal 13 Juli 2021).

[7] Holmgren, Jennifer, C. Gosling, R. Marinangeli, and T. Marker, "A New Development in Renewable Fuels: Green Diesel," UOP.LCC. Des Palines, Illonis, USA, 2007

[8] R. Irzon, "Perbandingan Caloric Value Beragam Bahan Bakar Minyak yang Dipasarkan di Indonesia Menggunakan Bomb Kalorimeter," Jurnal Sumber Daya Geologi, vol.22, no. 4, pp. 217-223, 2012

[9] N. Izza, "Aplikasi Gelombang Ultrasonik Pada Proses Pengolahan Biodiesel Berbahan Baku Jarak Pagar (Jatropha Curcas L)," Universitas Brawijaya: Malang, 2011.

[10] Kalnes, N. Tom , K. P. Koers, T. Marker, and R. D. Shonnard. "A Technoeconomic and Environmental Life Cycle Comparison of Green Diesel to Biodiesel and Syndiesel," Willey InterScience: Department of Chemical Engineering, Michigan Technological University, Houghton, MI, 2009.

[11] Kementrian ESDM. 2020. "Perkuat Ketahanan Ekonomi, Porsi EBT Ditargetkan 13,4 Persen pada $2020, "$

http://ebtke.esdm.go.id/post/2020/02/07/2472/perkuat.ketahanan.ekonomi.porsi.ebt.ditargetkan.134.perse n.pada.2020?lang=en. (Diakses pada 10 Maret 2020_.

[12] Patel, Madhumita and A. Kumar, "Production of renewable Diesel Through The Hydroprocessing of Lignocellulosic Biomass-Derived Bio-Oil : A Review," Renewable and Sustainable Energy Reviews, vol. 58, pp. 1293-1307, 2016

[13] Salamah, Siti and M. Setyawan, "Karakteristik Reaktor Hidrogenasi Minyak Biji Kapuk untuk Pembuatan Green Diesel". Universitas Ahmad Dahlan: Yogyakarta, 2013

[14] S. Fathona. "Ekstrasi Biji Bintaro (Cerbera manghas lactaria) sebagai Bahan Baku Pembuatan Biodiesel," Palembang: Politeknik Negeri Sriwijaya, 2019 
[15] Setiawan, E., \& Edwar, F. 2012. Teknologi Pengolahan Biodiesel dari Minyak Goreng Bekas dengan Teknik Mikrofiltrasi dan Transesterifikasi sebagai Alternatif Bahan Bakar Mesin Diesel. Jurnal Riset Industri Vol.VI No.2, 117-127.

[16] Syarifudin, dkk. 2019. Pengaruh Viskositas Biodiesel Campuran Solar-Minyak Sawit-Alkohol Terhadap Potensi Penurunan Performa Dan Peningkatan Emisi Jelaga. Politeknik Harapan Bersama Tegal. 